\title{
Review
}

\section{Race- and Sex-Based Disparities in Alzheimer's Disease Clinical Trial Enrollment in the United States and Canada: An Indigenous Perspective}

\author{
Nancy L. Olson ${ }^{\mathrm{a}, *}$ and Benedict C. Albensi ${ }^{\mathrm{a}, \mathrm{b}, *}$ \\ ${ }^{a}$ Division of Neurodegenerative Disorders, St Boniface Hospital Albrechtsen Research Centre, Winnipeg, MB, \\ Canada \\ ${ }^{\mathrm{b}}$ Department of Pharmacology \& Therapeutics, Max Rady College of Medicine, University of Manitoba, \\ Winnipeg, MB, Canada
}

Accepted 9 July 2020

\begin{abstract}
Randomized clinical trials (RCT) involve labor-intensive, highly regulated, and controlled processes intended to transform scientific concepts into clinical outcomes. To be effective and targeted, it is imperative they include those populations who would most benefit from those outcomes. Alzheimer's disease (AD) is most detrimental to the aging population, and its clinical manifestation is influenced by socio-economic factors such as poverty, poor education, stress, and chronic comorbidities. Indigenous populations in the United States and Canada are among the minority populations most influenced by poor socio-economic conditions and are prone to the ravages of $\mathrm{AD}$, with Indigenous women carrying the added burden of exposure to violence, caregiving stresses, and increased risk by virtue of their sex. Race- and sex-based disparities in RCT enrollment has occurred for decades, with Indigenous men and women very poorly represented. In this review, we examined literature from the last twenty years that reinforce these disparities and provide some concrete suggestions and guidelines to increase the enrollment numbers in AD RCT among this vulnerable and poorly represented population.
\end{abstract}

Keywords: Aboriginal, Alzheimer's disease, gender, Indian, indigenous, Inuit, Metis, native, randomized clinical trial, sex

\footnotetext{
${ }^{*}$ Correspondence to: Nancy Olson, BSc, RT, CRQM, Clinical Study Coordinator, Division of Neurodegenerative Disorders (DND), 351 Tache Ave/Lab 4050, Winnipeg, Manitoba R2H 2A6, Canada. Tel.: +1 204235 3941; E-mail: nolson@sbrc.ca and Benedict C. Albensi, PhD, BCMAS, CRQM, Full Professor \& Manitoba Dementia Research Chair, University of Manitoba, Max Rady College of Medicine, Dept. of Pharmacology \& Therapeutics; Principal Investigator, St. Boniface Hospital Research, Everett Endowment Fund; Chair (Alzheimer's research), Division of Neurodegenerative Disorders (DND), 351 Tache Ave./Lab 4050, Winnipeg, Manitoba R2H 2A6, Canada. Tel.: +1 204782 3698; E-mail: balbensi@sbrc.ca.
}

\section{INTRODUCTION}

Alzheimer's disease (AD) is the most common form of dementia, accounting for 60-80\% of all cases [1]. It is a multi-factorial disease whose symptoms include cognitive dysfunction (verbal and spatial memory loss, behavioral changes, poor judgement, confusion, mood and personality changes, and social withdrawal) and neurodegeneration. It is not a normal part of aging although aging is the greatest risk factor for $\mathrm{AD}$ [2]. $\mathrm{AD}$ is the 6th leading cause of death in the United States (US) and 5th leading cause for those 
over 85 years old [1, 3, 4]. In Canada and globally, the numbers are equally distressing and expected to increase worldwide as the population ages.

Globally 50 million people have AD or a related dementia with 1 case diagnosed every 3 seconds [5]. The global numbers are expected to increase to 131 million by 2050 [5]. The worldwide costs of dementia are $\$ 818$ billion US [5]. If it were a country, it would be the world's 18th largest economy; if it were a company, it would be the world's largest by annual revenue, exceeding Apple (US $\$ 742$ billion) and Google (US \$368 billion) [5]. Currently in the US, 5.8 million people have AD, which is expected to climb to 14 million by 2050 [3]. Between the years 2000 and 2017, deaths from heart disease declined by 9\%, but deaths from AD increased by $145 \%$ [3]. In Canada the numbers are also bleak, with $>500,000$ current cases of dementia, increasing to 1.4 million by $2031[5,6]$.

Two unique proteins have emerged that are linked to $\mathrm{AD}$ and whose presence is considered part of the diagnostic criteria $[1,7-10]$. Amyloid- $\beta(A \beta)$ in an extracellular protein that forms when the larger protein amyloid- $\beta$ protein precursor $(\mathrm{A} \beta \mathrm{PP})$ cleaves into smaller fragments [11]. In $\mathrm{AD}$, these fragments aggregate between the neurons forming "plaques" which disrupt communication. A large number of drug trials have focused on clearing out these plaques. Tau is a normal intracellular protein that binds to microtubes inside the neurons to stabilize them [12]. In $\mathrm{AD}$, they become detached from the microtubes and form long threads called neurofibrillary tangles or "tau tangles". There is a strong affiliation between the presence of these proteins and the onset of $\mathrm{AD}$, and they often show up in PET and MRI scans of the brain decades before the onset of symptoms. In autopsied $\mathrm{AD}$ brains, however, $\mathrm{A} \beta$ plaques only show up in $20-57 \%$ of brains and tau tangles in 92-100\% of brains [12]. In fact, $30 \%$ of AD patients have no neuropathological changes at autopsy [9]. Some of these non-pathological "AD" patients may have a condition called "limbic-predominant agerelated TDP-43 Encephalopathy" (LATE) in which TDP-43 inclusion bodies may be present along with abnormal TDP-43 in nuclei and neurites of neurons, oligodendroglia, and astrocytes [13-16]. Other non-pathological dementia-type disorders include valosin-containing proteins, fused-in sarcoma inclusions, schizophrenia, normal pressure hydrocephalus, hippocampal sclerosis, or vascular dementia. Based on this, the two proteins ( $A \beta$ and tau) may not be the "magic bullet" to the development of a cure.
As it stands now, the failure rate for new drugs for $\mathrm{AD}$ in clinical trials is an astonishing 99.6\% [12]. Only one drug out of 244 drugs in 413 clinical trials between 2002 and 2012 received FDA approval [12]. There are only four current drugs in use: three cholinesterase Inhibitors which include donepezil and rivastigmine for all stages of $\mathrm{AD}$ and galantamine for mild to moderate $\mathrm{AD}$; and one N-methyl-Daspartate (NMDA) receptor antagonist which include memantine and donepezil/memantine combination for moderate to severe AD [4]. Despite the lack of success, one more drug, aducanumab, has re-emerged as a potential drug therapy and is currently awaiting FDA approval.

Based on current drug failure data [11, 12, 17-20], and the urgency among the $\mathrm{AD}$ research community to find a cure, researchers are starting to think "outside the box" and many new disease theories have emerged that are actively being pursued. They include the following [12]: 1) $\mathrm{A} \beta$, tau, and phosphorylated tau; 2) Co-pathologies involving $\alpha$-synuclein and TDP-43; 3) Epigenetics involving presence of the Apolipoprotein $(A P O E) \varepsilon 4$ allele, affiliated with earlier $\mathrm{AD}$ and more severe cognitive decline; 4) Neuroinflammation in the microglia; 5) Mitochondrial dysfunction; 6) Synapse Loss; 7) Vascular changes; 8) Endosome dysfunction; 9) Brain hyperactivity/connectivity; and 10) Lifestyle factors.

Epigenetics is responsible for non-modifiable risk factors, specifically the race and sex a person is born with [21, 22]. And lifestyle factors, often dependent on socio-economic conditions, lead into the subject of this review paper. The minority populations in the US and Canada, including the Indigenous, suffer from greater poverty, violence, co-morbidities, obesity, hypertension, alcohol abuse, stress, diabetes, cardiovascular disease, and poor education than do the white majority. If a cure or treatment for $\mathrm{AD}$ is going to be found, and with greater funding recently put into AD research in both the US [23, 24] and Canada [25-28], the need for more targeted and focused clinical trials in critical. For a long time, race-based and sex-based disparities have occurred in clinical trials to the degree that many drugs and interventions approved for humans may not work in the populations they would most benefit [29-37].

For this review, we examined literature (PubMed and Google) within the last 20 years that have brought to light the progress or lack thereof in the area of clinical trial enrollment of Indigenous populations and Indigenous women in particular, and have provided guidelines on how to improve numbers. 
We have reviewed peer-reviewed journal articles, reviews and systematic reviews, government policy, and other guidance documents. Grey literature included websites, blogs, panel discussions, conference presentations, and book chapters. Historical references were used if applicable to our understanding of the current mistrust between Indigenous populations and the governments that oversee their care.

\section{NOMENCLATURE}

For consistency and clarity, the term "Indigenous" is used in general discussion throughout this review. This term refers to the entire Native population based in the US and Canada (i.e., those populations native to the land before the arrival of Europeans and other explorers). Specifically, Indigenous populations are communities that live within, or are attached to, geographically distinct traditional habitats or ancestral territories, and who identify themselves as being part of a distinct cultural group, descended from groups present in the area before modern states were created and current boundaries defined [38, 39]. The term "Aboriginal" is more commonly used in Canada and is the legal term from the Canadian Constitution Act (section 35), 1982 [39, 40]. However, the term "Indigenous" is more common globally [41]. Within these Indigenous populations, multiple groups emerge that will be described in more detail and will be based on specific publications and literature that refer to them.

\section{CLINICAL TRIAL CHALLENGES}

Randomized clinical trials (RCT) are a necessary part of clinical research. The only way to translate basic research into clinical outcomes is to perform highly disciplined, controlled, randomized human trials. Their intent is to represent the human population as a whole. However, race- and sex-based disparities in RCT enrollment have occurred for decades. To understand the challenges of enrollment in clinical trials for minorities, and minority women in particular, it is prudent to understand what type of challenges face the research team, sponsor, trial site, Institutional Review Boards, and ethics committees.

\section{General RCT challenges}

In the US, the Department of Health and Human Services (HHS) for which the National Institutes of
Health (NIH) falls under, has set a "2025" deadline in which to find a "disease modifying treatment or cure" for $\mathrm{AD}[23,28]$. Canada as a member of the G-8 has committed to this "2025" goal and also support the World Health Organization (WHO) "Global Action Plan on the public health response to dementia (2017-2025)" [28, 42]. In the US, two draft bills for NIH funding in 2019 would bring the total AD funding to $\$ 2.3$ billion [23]. This type of funding is unprecedented since the wars on cancer in 1971 and AIDS in the 1980s.

In a recent search of the ClinicalTrials.gov website, 2,301 clinical trials for AD were registered globally of which 1,188 were in the US and 203 in Canada [43]. RCTs fall under three categories: 1) interventional which include drug/biological, behavioral/other, surgical procedure, device; 2) observational; and 3) expanded access. All trials face the same challenges, which include trial complexity, government regulations, spiraling costs, staff roles and responsibilities, technological challenges, governance and oversight, and patient access [44, 45]. Enrollment is one of the biggest challenges faced. Twenty-seven percent of all trials fail to enroll a single participant [46] and some trials only recruit 0.2 patients per site per month, which would take 2-3 years to recruit for a 6-month trial [47]. One in every 200 Americans would have to enroll in a RCT to cover the number of participants required [46]. Lack of educational opportunities, poor socioeconomic conditions, and language barriers can reduce connectivity to the health care system and thus awareness of and knowledge of clinical trials and understanding of recruitment materials [48-51]. Other concerns include the lack of relevance of clinical trials. Heneghan et al. stated that there is a "lack of relevance to patients and decision-makers" and that in 57 drug trials for $\mathrm{AD}$, less than half (46\%) discussed the clinical significance of the results [52]. There is also a lack of external validity and "efficacy is not being translated to effectiveness" [53]. Other concerns include lack of involvement of Primary Care Physicians (PCP) in the enrollment process, lack of experience and expertise in the RCT workforce, and a lack of funding from the NIH that only covers $20-40 \%$ of the actual trial costs [48].

\section{Age-specific RCT challenges}

$\mathrm{AD}$ research is unique in that the population required for an RCT are sometimes older ( $\geq 65$ years for some trials). Ageism has long tainted RCT participation as the majority of trials have age-specific 
requirements, usually between 18 and 64 years [54]. By 2030, all baby boomers will be $>65$ years old [55] and more than 3 million people in the US over 85 will have AD. Therefore, the pool of participants to draw from is immense; however, many barriers to participation exist in the older population. Firstly, $20-30 \%$ of older adults refuse to partake in a RCT compared to $5-10 \%$ in the general population [51]. Banzi et al. noted age-specific challenges in AD RCT, in which only $8 \%$ of RCT participants were $>85$ years, despite those 80 and over representing $72 \%$ of $\mathrm{AD}$ patients [56]. In non-AD cancer, diabetes, and heart trials, over half have specific age limits and $20 \%$ of Phase III and IV trials exclude older adults based on age alone [49, 57]. This is especially troubling for those $\mathrm{AD}$ patients with early onset symptoms. There is also a perceived vulnerability in this population, access barriers, higher mortality rates, greater co-morbidities, and more drug usage [49, 58-60]. Other barriers include long complex documents and complicated language in the informed consent process and other trial processes [49]. As per Mody et al., there must be age-specific recruitment strategies put into place including the preparation of budget, staff, protocols, informed consent, and study materials designed to recruit and retain an older population [50]. Incentives including meal tickets, money, parking and transportation costs, and flexible scheduling are important in this population [50].

\section{AD specific RCT challenges}

AD-specific RCTs present another challenge, as this population is in cognitive decline. Only 10-13\% of the $\mathrm{AD}$ population is even eligible for clinical trials [61]. In addition, there is a high risk to sponsors in $\mathrm{AD}$ research as drug development takes 10-15 years and a high failure rate in a RCT means high costs to the drug company [62]. The concern in AD trials is whether the participant, cognitively poor to begin with, can maintain a RCT schedule and survive until the end of the trial [62]. Recruitment of the $\mathrm{AD}$ population and enrollment in an RCT requires an advocate to help with the Informed Consent process, thus you are "enrolling" two people and not one. The advocate often works and has a schedule which dictates the hours of operation to complete the $\mathrm{RCT}$, and has influence over medical care decisions during the trial [61-63]. Recruitment strategies have been implemented to increase RCT enrollment from this population, and include PCP involvement, public awareness campaigns, improved access to trials and studies, better design of documents, increased funding, and more lax exclusion criteria so as not to exclude co-morbidities and drug usage that are higher in this vulnerable population [61-64].

\section{RACE-BASED DISPARITIES IN AD CLINICAL TRIALS}

Racial minorities are currently underrepresented in clinical trials in $\operatorname{AD}[29,31,33,34,37,65,66]$. Since there is a projected large increase in minority populations in the US and Canada, low recruitment in RCTs for AD is of concern. In the US, the increase in minority populations $\geq 65$ years of age between 2014 and 2060 can be estimated based on Medicare Fee-for-Service (FFS) beneficiaries for this group in 2014 and the US Census estimates for race-specific projections [67]. The estimates are as follows: $75 \%$ increase for non-Latino whites, $172 \%$ for African Americans (AA), 274\% for American Indian/Alaska Native (AIAN), and 391\% for Latino Americans [67]. The percentage of individuals within these populations who survive to age 65 dementia-free but develop $\mathrm{AD}$ within the next 25 years are: $38 \%$ of AA, $35 \%$ of AIAN, $32 \%$ of Latino, $30 \%$ of whites, $28 \%$ of Asians, and $25 \%$ of Pacific Islanders (PI) [34].

Therefore, enrollment of racial minorities in $\mathrm{AD}$ RCTs must increase if trials are to be relevant. Much has been written about the lack of recruitment in these populations, although most articles are specific to the AA and Latino populations, with little written about Indigenous populations. Some recruitment-specific publications are not specific to AD. Pariera et al. in 2016 examined the willingness of racial minority populations to participate in a cancer clinical trial [34]. She noted that only $5 \%$ of eligible participants enroll in an RCT and of those, only $10 \%$ are ethnic minorities [34]. In a systematic review by GilmoreBykovskyi et al. on the recruitment and retention of underrepresented populations in AD research, 22 eligible studies were examined with only 7 focused on recruitment [31]. Quality and quantity of evidence to inform best practice in inclusion of minorities was low [31]. None of these studies included Indigenous participants.

\section{United States' indigenous populations}

\section{US: Demographics}

The US has three distinct indigenous populations: American Indian (AI) also called the Native American, the Alaska Native (AN), and the Native 
Hawaiian and other Pacific Islander (PI) group. In publications, census data, and other statistical references, the AI and AN are usually lumped together and called the "American Indian/Alaska Native" (AIAN). The Pacific Islander group includes Hawaiian, Samoan, and Tongan descendants, along with Asian populations. Little research has been done in these populations, and most literature reviewed in this paper focus on the AIAN group. Based on the US Department of HHS Office of Minority Health report from 2017 [68], the AIAN population was 5.6 million alone or in combination with one or more races, accounting for $1.7 \%$ of the US population. This number differs from other references including the Profile America Facts for Features article from October 2018, which states that 6.8 million people are of AIAN descent, including those of more than one race [69]. Whatever the current population number, the projected population estimate is the same: $>10$ million by $2060[69,70]$. Overall, there are 326 reservations, with 573 federally recognized tribes and 100 state recognized tribes that speak more than 200 languages $[68,70,71]$. Alaska contains the highest proportion of native populations at $19.5 \%$, followed by Oklahoma (13.6\%), New Mexico (11.8\%), South Dakota (10.3\%), and Montana (8.3\%) [70]. Seventyeight percent of the AIAN population live off-reserve, with $22 \%$ on reserves. Sixty percent of the AIAN population reside in metropolitan areas, the lowest percentage among all racial minority groups [68]. Approximately, 569,000 AI and AN alone or in combination were $\geq 65$ years of age in 2015 and the oldest cohort, aged 85 and older, is expected to increase sevenfold by 2050 [72].

\section{US: AD statistics}

Only recently, the life expectancy of the AIAN has approached that of non-Latino whites [73]. The life expectancy for the AIAN in the 1940s was 51 years, but in the 1990s increased to 70 years. The number of AIAN elders will double by 2030 from 2016 levels, which increases their risk of AD by virtue of age [73]. Although the current prevalence of $\mathrm{AD}$ and related dementias (ADRD) in the AIAN is less than AA, Latino Americans, and non-Latino whites based on Medicare FFS claims [67], the AIAN have a $35 \%$ greater risk than non-Latino whites of acquiring AD over a 25-year period after age 65 [34]. This risk value is based on a publication by Mayeda et al. that examined dementia incidence between 2000-2013 along with 25-year cumulative risk in 274,283 healthcare members aged 64+ in California among six racial groups, stratified by age and sex [74]. However, the actual AD risk may be skewed based on the "certificate of degree of Indian blood" (CDIB) present in a particular tribe [75]. So-called pure blood natives rarely have the $A P O E$ e4 allele associated with increased risk of $\mathrm{AD}$, and thus may have lower $\mathrm{AD}$ numbers than those without pure blood [75, 76]. Despite the presence of pure blood natives in the population, between 2014 and 2060, it is estimated that the numbers of AIAN $\geq 65$ years of age diagnosed with $\mathrm{AD}$ will increase fivefold [67, 72]. In the younger age group ( $\geq 45$ years), one in every six AIAN reported "subjective cognitive decline" (SCD), which is a set of self-reported problems with memory $[51,72]$. Whatever the current numbers for $\mathrm{AD}$, those numbers may be underestimated in the US [71]. Reasons for this could include: lack of access to appropriate healthcare, competing risk factors for early mortality (accidents, suicides, infectious diseases), and the complexity of identifying $\mathrm{AD}$ in patients with vascular lesions from stroke [71].

\section{US: AD risk factors}

According to the WHO, "The social determinants of health are the conditions in which people are born, grow, live, work and age. These circumstances are shaped by the distribution of money, power and resources at global, national and local levels. The social determinants of health are mostly responsible for health inequities - the unfair and avoidable differences in health status seen within and between countries".

There are specific risk factors in the AIAN population that may increase the prevalence of AD. The AIAN cannot control non-modifiable risk factors such as age, race, sex, and presence or absence of the $A P O E \varepsilon 4$ allele, but many of the risk factors they face are based on underlying socioeconomic conditions and lifestyle choices. These risk factors may include:

Lack of recognition of cognitive decline. Unless an AIAN is willing to recognize cognitive decline as a sign of disease and seek treatment, $A D$ may go undiagnosed. The terms "Dementia" and "Alzheimer's Disease" are not easily translated into a common language understood or appreciated by Natives Americans and many tribes have defined and explained cognitive decline and memory loss in their own language based on history and culture [71]. Some of these explanations include: 1) "Naturalization" 
in which cognitive decline is part of the Creator's plan for ultimate learning; 2) An imbalance in a person's spiritual, emotional, and social environment (the speaking of negative consequences of illness has broken a cultural taboo and caused the illness); 3) Communication with the spirit world (a "crossing over" into the next world); and 4) Dementia is a conflict between traditional and non-traditional ways of life. These explanations may delay a tribe member from seeking professional medical help and delay the diagnosis and treatment of AD.

Poverty, income, and lack of education. Natives have higher poverty levels and lower educational achievement than any other ethnic group in the US [71]. The median income of a single-race AI and AN household in 2015 was $\$ 38,530$ compared to $\$ 57,775$ for the nation as a whole [70]. $26.6 \%$ of single-race $\mathrm{AI}$ and AN were in poverty in 2015 [70]. The rural AI population is considerably poorer than the urban population [71]. Rural native elders have $70 \%$ or less of the per capita income of urban elders [71]. In terms of education, $19.6 \%$ of AIAN aged 25 and over had at least a bachelor's degree, compared to $35.8 \%$ of non-Latino whites and only $6.8 \%$ of AIAN held an advanced graduate or professional degree, compared to $13.8 \%$ of non-Latino whites [68].

Cardiovascular disease (CVD). Native Americans are more likely to be diagnosed with CVD than whites, and the three contributing risk factors for heart disease are more common in AIAN than whites: midlife obesity, higher blood pressure, and smoking [72, 77]. Mid-life obesity affects one in three AIAN over the age of 50; AIAN are 30\% more likely to have high blood pressure than whites; and AIAN have the highest smoking rates of any racial minority in the US with one in three in their 50s and one in four in their 60s smoking cigarettes [72]. In a 2002 study by Weiner et al. on the Choctaw Indians of Oklahoma, modifiable cardiovascular risk factors that include hypertension, elevated cholesterol, diabetes, myocardial infarction, and obesity are higher in the Choctaw tribe than the white population [78].

Other risk factors. Tuberculosis rates were four times higher in AIAN than whites in 2017 (incidence rates of 3.9 versus 0.5 , respectively) [68]. In fact, American Indians are 500 times more likely to die of tuberculosis than non-natives [79]. Other risk factors include cultural barriers, geographic isolation, and inadequate sewage disposal [68]. Of those AIAN over 5 years of age, $26.9 \%$ spoke a language other than English at home [80]. This complicates the diagnosis of $\mathrm{AD}$, which often relies on cognitive testing formats presented in English. Diabetes also increases the risk of AD in the AIAN communities. Native Americans are 177 times more likely to die of diabetes than non-natives [79]. The Gerontological Society of America published a Special Issue in 2015 that looked at Depression and Dementia among the AIAN population; depression, linked to higher diabetes rates, is expected to affect 81,702 AIAN by 2050 [81].

\section{US: AD clinical trial challenges}

Indigenous populations in the US are poorly represented in RCTs. We searched the ClinicalTrials.gov website for trials specific to $A D$ and specific to American Indigenous populations. Using the terms "Alzheimer's Disease", "Dementia", and "Memory Loss" for the Condition or Disease title in combination with "Indigenous", "American Indian", "Indian", "Native American", "Alaska Native" and "Pacific Islander", we found only one clinical trial that is not yet recruiting [43]. The RCT titled "Alzheimer's Disease and Precision Medicine Research with American Indian and Alaska Native People" (NCT03448601) was first posted on February 28, 2018. This is a University of Colorado sponsored RCT (with collaboration from Washington State University and the University of Arizona) in which 3,000 AIAN participants, aged 18-100 years of both sexes will be recruited. This mixed-method, multi-state study will develop and evaluate culturally tailored recruitment materials and test their effectiveness for: a) engaging AIAN participants in a culturally tailored recruitment and engagement module focused on AD and Precision Medicine (AD-PM); b) enhancing enrollment in AD-PM clinical trials; and c) improving knowledge and attitudes about AD and PM. Because recruitment into RCTs is the greatest challenge for most studies, this trial will provide some much-needed information for the $\mathrm{AD}$ research community. Poor recruitment into RCTs by the Indigenous in America are partly caused by their inherent mistrust of the federal government and the institutions they support. There is a distinct history between natives and the government, starting with "destruction of entire native populations", colonization, treaties, forced relocation, and attempts at assimilation through the removal of their children and the impact of missionaries [71]. Boarding school practices in the first half of this century are among recent events that have caused considerable trauma to the mental health of AIs [71, 82]. Alaska Natives that experienced boarding school described post-traumatic stress disorder, social phobias, 
contemplation of suicide, damage to sense of identity and well-being, alcohol abuse, emotional scars, difficulty integrating back into family and community, loss of culture, loss of language, feeling like strangers in their home, and failure to learn parenting skills [82]. Other past wrongs included the forced sterilization of indigenous women in the 1970s without consent and the misuse of blood samples from nearly every Havasupai tribe member of Arizona [83]. Other historical wrongs included the giving of "smallpox blankets" to the Haudenosaunee peoples of New York by Sir Jeffery Amherst and the use of "Indian" mascots by sports teams [65].

When AI individuals were asked why they don't participate in a RCT, some of their responses included: 1) They don't want to be "guinea pigs"; 2) The study findings are rarely shared with the community; 3) The study findings rarely improve local services; 4) The promised study benefits rarely reach the AI community; and 5) Access to resources which allow community members to partake (e.g., transportation) are lacking [65, 83]. Other barriers to research include distance from study sites [84, 85], patients not being informed of availability of trials, and the need for approvals from the Tribal/IHS (Indian Health Service) Institutional Review Board and Tribal Research Committee for a trial offered in a tribal clinic [84]. Also, universities that often run a RCT are viewed as elitist and not committed to the welfare of minority communities [86].

\section{Canada's indigenous populations}

\section{Canada: demographics}

The Indigenous or Aboriginal populations in Canada consist of three main groups: First Nations (Indian), Metis, and Inuit (or Inuk). The First Nations are equivalent to the American Indian or Native American group in the US. The Metis are descendants of early 17 th-century relationships between North American tribes and Europeans, often of French descent. Inuit is an Inuktitut word meaning "the people" and refer to those that live mainly in four polar and circumpolar regions of Canada called (from west to east); Inuvialuit, Nunavut, Nunavik, and Nunatsiavut $[39,87]$. Neither the Metis or Inuit are protected under the Indian Act, created in 1867 to "colonize" the First Nations peoples [39, 88]. Reserves were created and held by the Crown (Canada is a British Commonwealth country) and administered based on treaties. Only those with registered Indian Status (i.e., Status Indian) may own land on a reserve [89].
The 2016 Canadian Census listed 1,673,780 Indigenous peoples in Canada, which then represented $4.9 \%$ of the population. Approximately $58.2 \%$ were First Nations ( $76.2 \%$ of these registered or treaty status); 35.1\% were Metis; and 3.9\% were Inuit [90]. Between 2006 and 2016, the Indigenous population increased by $42.6 \%$, almost four times the rate of the non-Indigenous population, with Metis leading the increase at $51.2 \%$ compared to First Nations $(39.3 \%)$ and Inuit (29.1\%) [87]. There are more than 600 unique First Nation/Indian bands that represent more than 50 nations and speak more than 70 languages [87]. Like the rest of the world, the Indigenous population in Canada is aging. In 2006, $4.8 \%$ of the Indigenous were $>65$ years of age. By 2016, this number increased to $7.3 \%$ [87]. Within the First Nations, $44.2 \%$ lived on reserves in 2016 [89]. These reserves are geographically dispersed from coast to coast to coast in the second largest country (by area) in the world. This geographical isolation alone makes recruitment into an RCT a unique challenge in Canada.

\section{Canada: AD statistics}

Since Indigenous elders are among the most at risk and frail of the population, their $\mathrm{AD}$ numbers are expected to increase. One estimate indicates that ADRD cases are expected to increase by 3.3 -fold in the Inuit and 4.2-fold (with increases to 4.8-fold on reserves) in First Nations by 2031 from 2006 levels [91, 92]. In a report on the Six Nations of Ontario in 2014 on ADRD, caregivers from the medical community suspected that $25 \%$ of their patients had AD; however, effective training of clinical staff in the diagnosis and treatment of AD and a definitive diagnosis from a doctor is lacking in many communities [93].

\section{Canada: AD risk factors}

Risk factors for AD in the Indigenous in Canada can be categorized as: 1) Modifiable risks; high cholesterol, increased blood pressure, diabetes, smoking, obesity, diet, and inactivity; 2) Partially modifiable risks; alcohol usage, reduced education, depression, and traumatic brain injuries; and 3) Nonmodifiable risks; age, genetics, family history, and gender [91]. Indigenous populations cannot control their race, family history, sex or age, but many of the modifiable and partially modifiable risk factors occur in higher numbers and more severely impact the Indigenous populations than the non-Indigenous populations [39, 91, 92, 94, 95]. Modifiable risk 
factors may account for $75 \%$ of all $\mathrm{AD}$ in Indigenous people [96]. Some of these risk factors may include:

Memory loss. On reserves in particular, memory loss associated with $\mathrm{AD}$ is often considered a "normal part of aging", a part of the "circle of life", or a "return to childhood" $[92,93]$. So long as there is no title attached to memory loss (such as "Dementia" or "Alzheimer's Disease"), there is no stigma associated with it. This "childishness" and the presence of hallucinations can be seen as a return to the Spirit World and the Creator [93]. Often, elders will recommend "Red Whip Tea" (red willow) or a traditional "Eagle Dance" to help with forgetfulness. This view of memory loss is a risk factor, as Indigenous are less likely to seek help and get a proper cognitive screening test and diagnosis by a doctor. By the time they are properly diagnosed, their condition may be quite advanced and their long-term quality of life jeopardized.

Frailty. Frailty can be defined as having: exhaustion, shrinking, weakness, slowness, and low activity [49]. It is an accumulation of health problems and conditions referred to as "deficits". In an Ontario First Nations Ageing Study, 25\% of First Nations aged 75 and up had 5 or more chronic conditions [95]. Many Indigenous elders have had a difficult life due to their socio-economic conditions, including racial discrimination and the burdens of colonialization and thus experience more frailty and have a higher number of co-morbidities than non-Indigenous elders [95]. First Nations groups in Ontario experience frailty at a younger age than the general Canadian population [95]. Frail Indigenous are associated with poorer nutrition, lack of paid employment, use of illegal drugs, and are 1.7 times more likely to have parents that attended Residential Schools, and 2.4 times more likely to go to Traditional Healers for treatment rather than a licensed physician [95].

Diabetes. Diabetes increases the risk of AD by twofold [91] and First Nations populations are 3-5 times more likely to have diabetes than the general Canadian population [96]. Indigenous have higher rates of obesity, physical inactivity, and smoking than non-Indigenous, all of which are risk factors to acquire diabetes [96]. In 2008/2009, the agestandardized rates of diabetes were $17.2 \%$ in First Nations on reserves, $10.3 \%$ in First Nations offreserve, $7.3 \%$ in the Metis, and 5\% in the Inuit and general populations [91].

Lack of trust in the medical field. Most doctors, nurse practitioners, nurses, and caregivers on reserves are non-Indigenous and don't speak the same language or have the cultural sensitivity training required to understand and appreciate the population they serve [96]. There is also a lack of geriatric resources, a high turnover among staff uncomfortable working on remote northern reserves, and a cultural insensitivity to elders in the population. Many nurses make the diagnosis in the absence of a doctor, and are not well trained to diagnose AD specifically when patients present with different chronic conditions or have normal memory loss caused by aging [91]. In addition, there is a high degree of mistrust with the federal government who run the health care systems on reserves. The Indian Act of 1867 that provided the "protection, assimilation and Christianization" of First Nations [88, 89], along with Residential Schools, the 60's Scoop (in which Indigenous children were "scooped" from their homes and fostered or adopted into primarily middle class white families), and gender discrimination $[88,94]$ have all led to a mistrust in the Healthcare system especially by on-reserve Indigenous across Canada.

Other risk factors. Other AD risk factors affecting the First Nations, Metis, and Inuit in Canada include high cholesterol, CVD, hypertension (high blood pressure), lack of immunizations, poor dental health, depression, reduced education, post-traumatic stress, alcohol, poor diet, and exposure to toxins [91, 92, 95, 96].

\section{Canada: AD clinical trial challenges}

Previously we listed general challenges to recruitment and retention into an RCT, along with age-specific and AD-specific challenges. Add to this geographical isolation and separation of Indigenous peoples across a very large country and generalized mistrust of the healthcare system, as well as poor knowledge and understanding of $\mathrm{AD}$, and recruitment into an RCT takes on a whole new level of challenge.

We searched the ClinicalTrials.gov website for trials specific to $\mathrm{AD}$ and specific to the Canadian Indigenous populations. We used the terms "Alzheimer's Disease", "Dementia", and "Memory Loss" for the Condition or Disease title in combination with "Indigenous", "Aboriginal", "First Nation", "Metis" and "Inuit"; here we found no ongoing clinical trials [43]. This lack of enrollment within Canada for AD specific RCTs reflects a deep-seated problem within the Indigenous communities as far as basic access to medical care and the proper knowledge of, diagnosis and treatment of $\mathrm{AD}$, required before any enrollment into an RCT can occur [91-98]. According to the National Aboriginal Health Organization, "Aboriginal peoples have been studied to death, and 
many are disillusioned by research reports published by people who don't know much about their lives and have little concern about the impact of the results on their community" [97]. This may be the case; however, most research studies from the last few decades have involved interviews, observations, and questionnaires, and were not highly regulated and controlled RCTs for new AD drugs or interventions.

This is not to say that RCTs with Indigenous populations in Canada have never taken place. In the excellent publication titled "A Systematic Review of Randomized Controlled Trials of Health-Related Issues Within an Aboriginal Context" from the National Collaborating Centre for Aboriginal Health (NCCAH), a review of all RCTs involving Aboriginal populations was undertaken. The review, based on the Cochrane and Campbell Collaborations method, found that only 35 such RCTs have been published worldwide in the past four decades, with only 6 in Canada [66]. These involved the Ojibway-Cree First Nation in Ontario, the Sagkeeng First Nation Ojibway in Manitoba, the First Nation People registered with the Battlefords Tribal Council in Saskatchewan, and an Inuit community in Nunavut [66]. None of these trials involved $\mathrm{AD}$ or dementia. This is not to say that AD specific or other RCTs have not occurred, as many trials fail to enroll participants or the results are never published.

\section{SEX-BASED DISPARITIES IN AD CLINICAL TRIALS}

It is important to differentiate "sex" and "gender". The US Institute of Medicine clarified the difference between sex and gender in a 2010 report [99]. "Sex" refers to the classification of living things as male or female according to their reproductive organs and functions assigned by chromosomal complement (e.g., XX versus XY), and "gender" refers to a person's self-representation as male or female or to how that person is responded to by social institutions on the basis of that presentation [99]. Little attention has been paid to etiology of disease including $\mathrm{AD}$, based on the presence of two X chromosomes, one maternal and one paternal, versus only one in males.

Currently, more women than men have AD in both the US and Canada, with approximately $2 / 3$ of all AD cases being women $[3,100,101]$. The estimated lifetime risk for $\mathrm{AD}$ at age 45 is approximately one in five $(20 \%)$ in women and one in ten $(10 \%)$ in men [102]. However, like racial minorities, women have been underrepresented in many RCTs [103-106]. Much of this disparity in RCT enrollment goes back to the mid 1900s when problems with the drugs thalidomide and diethylstilbestrol (DES) brought to light the need to protect fetuses in future clinical trials [106]. Thalidomide, used to treat morning sickness in the early 1960s, led to malformed fetuses, and DES, used in the 1930s to prevent miscarriages, led to problems 30 years later in female offspring [106]. These serious health issues led to a change in FDA guidelines in 1977 that excluded premenopausal women capable of becoming pregnant from partaking in Phase I and Phase II clinical trials [106]. Although the FDA reversed their 1977 guidelines, and the NIH in the US and the Canadian Institutes of Health Research (CIHR) in Canada introduced mandates in 2016 to include both sexes in research [107], there continues to be a sex-based disparity in RCT enrollment numbers and a lack of proper stratification of data by sex $[100,103]$.

\section{Sex-based disparities in ad animal model studies}

Clinical trial design is often based on what happens in the laboratory using animal models. AD-specific transgenic mouse models were developed over 20 years ago with the intent of mimicking the neuropathological changes seen in human AD patients, including the presence of plaques and tangles [108]. Surprisingly in the decades since, no new therapies for $\mathrm{AD}$ have been introduced in the clinic, and the two current classes of AD drugs (acetylcholinesterase inhibitors and memantine) were never tested in transgenic mice prior to clinical testing [108]. This lack of success in animal models for AD drug development has several explanations. One is that the majority of widely used transgenic mouse models are designed based on the genetics of familial AD (early onset; autosomal dominant) which represents less than $1 \%$ of AD. Another reason could be the lack of sexbased representation in animal research. As of August 2019, there were 177 AD animal models including transgenic and naturally occurring non-transgenic models [109]. The most common transgenic animal model used for AD-specific research are mice. Nontransgenic models include rats, guinea pigs, dogs, and primates [109]. Common genes expressed in these models include APP (amyloid precursor protein) alone or in combination with other genes as well as genes specific to the expression of tau, presenilin1, and presenilin2 [108, 110, 111]. 
Neuroscience research has been particularly biased against female-based animal research. Among 1,200 neuroscience papers (not AD specific) published between 2011 and 2012, only $42 \%$ reported on the sex of the animal used, and when reported only $24 \%$ of the animals were female [112]. In research papers in which sex is reported, male mice often outnumber female mice 5 to 1 . Researchers blame this bias on the estrous cycle in the female mouse, which occurs every 4 days, complicating research because experiments need to be done at each of the 4 cycles of estrous [112]. Researchers have thought that including females would cause an increase in sample size and the cost of doing research, though this is not necessarily the case [112-114]. Much research acts as if females are just "smaller men" that don't require special attention [112]. It turns out that females are quite different than males, in $\mathrm{AD}$ and other diseases. When the University of California looked at the expression of 23,000 genes in the brain, liver, fat and muscle tissues in mice, there was a striking and measurable difference in more than half of the genes' expression between males and females [112]. It should be noted that although the NIH mandated the inclusion of women in RCTs as far back as 1993, few guidelines existed for laboratory-based research [115]. In Canada, however, the Women's Brain Health Institute, in collaboration with the Alzheimer's Society of Canada and the Canadian Consortium on Neurodegeneration in Aging (CCNA), tackled the sex gap by "stating" in 2012 that anyone using CCNA data must report the sex of the animal they are using [116].

Over the last few decades, AD researchers have noticed sex-based differences in AD mouse models [117-122]. Bories et al. used a social interaction paradigm to assess social dysfunction in male and female triple-transgenic mice $(3 \times \mathrm{Tg}-\mathrm{AD})$ compared to sex-matched controls [117]. In transgenic mice, social disinhibition was noted at 18 months for males, but at 12 months for females who then showed reduced social interactions by 18 months. These psychiatric-like symptoms appeared to correlate with alterations in synapse activity [117]. It has also been noted that female mice exhibit more plaques and tangles than their male counterparts and females exhibit an earlier onset of neuropathology [120]. These pathological differences are not exhibited across all mouse models, therefore the model chosen can impact the interpretation of the results [120]. Dodiya et al. in 2019 noted that in the germ-free APPPS121 transgenic mouse model of $A \beta$ amyloidosis, an antibiotic cocktail (ABX) that induced changes in gut microbiome led to a reduction in $A \beta$ pathology and alterations in microglial morphology, but only in the brains of male mice and not female mice [119]. In another study, to test the theory that maternallyinherited mitochondrial dysfunction is associated with $\mathrm{AD}$ symptoms, gonadally intact female $3 \times \mathrm{Tg}$ $\mathrm{AD}$ mice 3, 6, 9, and 12 months of age were compared to non-transgenic female controls [122]. The AD mice showed decreased mitochondrial bioenergetics, increased oxidative stress and increased mitochondrial amyloid load. These changes appear to precede the formation of plaques in the brain [122]. Djordjevic et al. also looked at brain region and sex-specific alterations in mitochondrial function and NF- $\kappa$ B signaling in the TgCRND8 mouse model of AD [118]. There was an increase in the basal and coupled respiration in the hippocampus of TgCRND8 females only, and in females there was an increase in all three subunits of NF-k $\beta$ (p50, p65, and p105) but in males there was only an increase in two subunits (p65 and p105, but not p50) [118]. Yang et al examined sex differences in pathological changes and cognitive behavior in 12-month-old $3 \times \mathrm{Tg}$-AD mice compared to controls [121]. Female AD mice displayed more prominent amyloid plaques and neurofibrillary tangles, neuroinflammation and spatial cognitive deficits than their male AD counterparts.

These animal model experiments show that females and males are not the same when it comes to AD pathophysiology. No transgenic mouse model represents the human $\mathrm{AD}$ subject exactly, however distinct differences have been noted in animal-based models that suggest the importance of including women in equal representation in future AD RCTs.

\section{Sex-based disparities in AD human studies}

Over the past 20 years, numerous studies have identified differences between the sexes across the full spectrum of clinical manifestations of sporadic $\mathrm{AD}$ [123]. Men with $\mathrm{AD}$ are more likely to exhibit apathy, agitation, abusive, and socially inappropriate behaviors whereas women are often depressed, reclusive and exhibit emotional liability, delusions, affective (relating to mood, feelings and attitude) symptoms, and manic symptoms [123]. Regarding cognitive testing of non-cognitively inclined (NCI) persons, women consistently do better on verbal tasks and men do better in visuospatial and motor coordination [123, 124]. The brain itself shows physical differences between the sexes, with the male brain having a larger volume and more white matter and the 
female brain having more grey matter [100]. Some studies $[100,102,123,125,126]$ find a difference in the $A \beta$ plaque burden between human males and females, while other studies [102] do not show a clear distinction. In the ADNI (Alzheimer's Disease Neuroimaging Initiative) studies, cognitive deterioration was higher in women than men over one year and twice as fast over 8 years [123]. Regardless of the number of plaques in the brain, the impact of $\mathrm{A} \beta$ plaques appears to have greater significance in women. In one study reviewed by Ferretti et al., each additional unit of AD pathology (calculated as a global measure of the burden of neuritic plaques, diffuse plaques, and neurofibrillary tangles across four regions of the brain) was associated with $a>20$-fold increase in the odds of dementia in women and only a 3-fold increase in men [123]. Rachel Buckley et al. looked at the data for 296 clinically normal adults with higher amyloid burden, in which women showed higher entorhinal cortical tau signal compared to men with the same burden [127]. Mitochondrial dysfunction, which causes oxidative stress, may lead to the pathological changes seen in $\mathrm{AD}$ and women may be more influenced by these changes, perhaps because mitochondrial DNA is largely matrilineal (inherited from the mother) [100]. Socioeconomics can cause gender-related disparities in the manifestation of AD. Men have historically had higher education than women and more cognitively demanding jobs. Depression, midlife dyslipidemia, diabetes mellitus, and hypertension appear to be specific predictors for $\mathrm{AD}$ in women, whereas marital status and obesity are predictors in men [123]. For all these socioeconomic factors, the presence of the $A P O E \varepsilon 4$ allele may exert greater influence in women than men [123]. In fact, the $A P O E \& 4$ genotype may interact synergistically with alcohol consumption, smoking, physical inactivity and high saturated fat intake, and this synergy may have a greater influence on the transition from mild cognitive impairment to AD in women than men [117, 123]. Postmortem brain samples from 1,453 persons from two longitudinal community-based studies in older adults (Religious Orders Study [128] and the Rush Memory and Aging Study [129]) showed neuropathological changes in AD male and female brains, with women's brains having a higher density of tau tangles, more arteriolosclerosis and less gross infarcts [130].

\section{Why the differences between the sexes?}

Why do more women than men currently have AD? One obvious explanation is that women live longer than men, and those men that survive to older age have healthier hearts (no CVD) and are less likely to develop AD [123]. This may be true, but likely cannot explain the significant differences in AD numbers between men and women across all age categories. Some theories put forward include:

Loss of estrogen. The hormone estrogen is present in a high amount in premenopausal women, then drops drastically after menopause, right around the time the risk for $\mathrm{AD}$ increases in women. Estrogen has neuroprotective properties including: supporting growth and development of cholinergic neurons, increasing cholinergic activity, anti-oxidant properties through the upregulation of superoxide dismutase and glutathione peroxidase, alternative metabolism of amyloid resulting in reduced deposition of toxic $A \beta$, increased cerebral blood flow and glucose metabolism, and alterations to mitochondrial function [100, 131]. Whereas the drop in testosterone in men occurs slowly, the drop in estrogen occurs rapidly, which may explain the increased risk of $\mathrm{AD}$ in women [124]. The loss of estrogen may also be associated with reduced neurogenesis in the hippocampus that contains a high number of estrogen receptors and is important for the formation of new memories, along with a loss in plasticity and cognitive reserve $[124,132]$. There is a risk to females of increased $A \beta$ disposition, reduced FDG-glucose metabolism, and lower MRI grey and white matter, with menopause being the highest risk factor, followed by hormone replacement therapy (HRT), hysterectomy, and thyroid problems [133]. HRT may reduce the impact of estrogen loss and provide protection against the development of $\mathrm{AD}$, but is only effective within 5 years of menopause [46]. This is the "window effect" or "timing effect" theory, in which protection from HRT in older women is outweighed by detrimental effects including enhanced clotting and inflammation [131], along with increased incidence of breast and uterine cancers and an increased incidence of CVD [46].

Caregiver effect. $75 \%$ of unpaid caregivers for people with chronic debilitating diseases such as dementia are women [123]. This caregiver burden is associated with lower rates of employment and an increased prevalence of psychological AD risk factors, such as sleep disorders and depression, in women caregivers as compared to male caregivers [92, 123]. Dementia care, compared to caregiving for other illnesses, is a particularly demanding form of caregiving. According to a NAC/AARP survey, female dementia caregivers provided an average of 
24 hours of care per week, significantly more than other types of caregivers [131, 134]. More than half the dementia caregivers reported that they must maintain vigilance 24 hours per day. Compared to sons, daughters of $\mathrm{AD}$ patients provided more routine assistance, experienced more guilt, were less likely to receive support from their spouses, and were more likely to leave the labor market to care for their parent [102]. When the caregiver is a spouse, the risk is no less. Spousal caregivers may be at higher risk of cognitive impairment or dementia than non-caregiver spouses in response to psychosocial (e.g., depression, social isolation, and sleep problems), behavioral (e.g., exercise and diet), and physiological (e.g., metabolic syndrome and inflammatory) variables [102].

\section{Current AD RCT challenges with women}

Given the evidence that women are biologically different than men with regards to $A D$, what does this mean for future RCT enrollment? Historically, men, frequently of the Caucasian race, were considered the "normal" study population [103]. Researchers assumed women should have the same response to drugs as men, and women were considered confounding and more expensive test subjects because of fluctuating hormone levels. We now know that there are differences in the physiology of the sexes that may translate into differences in the pharmacokinetics and/or pharmacodynamics for specific drugs [103]. However, in a 2017 systematic review of sex and gender differences in 48 RCTs of three cholinesterase inhibitors (donepezil, galantamine, and rivastigmine) and memantine, including a total of 20,688 patients, only two studies investigated sex differences for safety and efficacy [123]. A second systematic study found an almost complete lack of data on sex differences in the adverse effects of cholinesterase inhibitors in clinical trials [123]. Therefore, even if we increase the numbers of women in AD RCTs, we must still strongly encourage researchers to extract critical sex-based results from their databases. In a review of nine medical journals in 2009 (not AD specific), most studies that were not sex-specific had an average enrollment of women of $37 \%$; however, $64 \%$ did not specify their results by sex and did not explain why the influence of sex in their findings was ignored [103]. In a systematic analysis of 277 stroke specific RCT registered on the ClinicalTrials.gov website from 1990-2018, the enrollment rate for females did not change significantly $(\sim 40 \%)$ and only $30 \%$ of the trials reported results according to sex [135]. Although Health Canada, the FDA, and the
NIH have all developed multiple policies designed to increase women's enrollment numbers in clinical trials and increase the presentation of RCT data stratified by sex, much work still needs to be done [103, 106]. Many publications have explored sex-based differences in $\mathrm{AD}$ along with sex-based disparities in $\mathrm{AD}$-specific and other RCTs, and all have come to the same conclusion: for future studies to be relevant, the number of women enrolled in RCTs need to increase and the management of data must include sex-specific analyses [100, 103-106, 123, 136].

\section{INDIGENOUS WOMEN AND AD CLINICAL TRIALS}

\section{United States}

We have discussed AD clinical trial challenges as they apply to Indigenous populations in the US and women in general. We know that only one RCT is currently registered on the ClinicalTrials.gov website that is specific to the AIAN. Given this, we need to increase enrollment of Indigenous populations, but Indigenous women in particular might be more susceptible than Indigenous men to the ravages of AD by virtue of their sex and the effects that socioeconomic inequities have on them. Several historical inequities have affected AIAN women more than men, and explain their deep-seated mistrust of government. Between 1973 and 1976, 3,406 native women were sterilized, $88.1 \%$ of them aged 15-44 years. Also, historically, attempts were made to assimilate natives through the forced removal of children from the tribe [71]. To lose one's child presumably creates stress, grief, and long-term health issues. Also, infant mortality rates are $60 \%$ higher in indigenous women than whites [79]. Another unique risk-factor for AIAN women is exposure to violence. Most elderly AIAN woman are mothers, grandmothers, aunts, or sisters and are more likely to be directly impacted by sex-based violence in their community. Even if they never experienced violence themselves, they are likely to know someone who has been affected and can feel their grief and loss of confidence and morale. A young girl on a reserve has a 1 in 3 chance of being sexually assaulted in her lifetime [79]. On some reserves, women are 10 times more likely to be murdered, and $84 \%$ of AIAN women experience physical, sexual, or psychological violence in their lifetime [137]. For more than 35 years, US laws have stripped native tribes of all criminal authority over non-natives, which reportedly 
represent $96 \%$ of all sexual assault assailants [138]. Between 2005 and 2009, US lawyers declined to prosecute $67 \%$ of Native American cases referred to them, and many cases were never investigated [138]. Native women and girls are also "disappearing" at an alarming rate due to human trafficking or other causes. In 2016, 506 Indigenous women and girls disappeared or were killed in 71 urban cities [137]. 5,712 Indigenous women and girls were reported missing in 2016; however, only 116 of these were logged into the US Department of Justice database [137]. The "Not Invisible Act of 2019" is designed to quicken the response of federal agencies by focusing on why girls and women are disappearing and where those being trafficked might be going [137]. Whether women are being assaulted, murdered, or just disappear, the remaining female members of their family often feel the greatest impact. Suicide rates in AIAN are $>3$ times the national average and domestic violence and sexual assault against women are two of the reasons cited, along with poverty, unemployment, and alcohol and drug abuse. All these risk factors can cause stress, depression and anxiety, and increase the risks of being diagnosed with AD. To add to these stresses, many elderly AIAN women are grandmothers looking after their grandchildren as well as their spouse. Of grandparents living on reserves with their own grandchildren under 18 years, $52.3 \%$ are responsible for their care [80]. This combination of historical inequity, domestic and sexual violence, caregiving stress, and poor legal protection have all created a mistrust that will no doubt impact recruitment and retention of this minority population in future AD RCT.

\section{Canada}

Like their American counterparts, Canadian Indigenous women suffer from socioeconomic conditions that may put them at a higher risk of developing AD [91, 139, 140]. Indigenous women experience lower quality housing, a poorer physical environment, lower education levels, a lower socio-economic status, and fewer employment opportunities than non-Indigenous women [140]. The 2002/2003 First Nations Regional Health Survey showed that 34.5\% of First Nation women were depressed at least 2 weeks a year versus $25.7 \%$ of First Nation men [91]. A 2012 Aboriginal People's Survey indicated that in First Nations, Metis, and Inuit nations, $>20 \%$ of adults had suicidal thoughts with women having a higher percentage than men [91]. Aboriginal women experience twice the rate of poverty and have higher rates of diabetes and obesity than non-Aboriginal women [140]. Two-thirds of First Nation peoples with diabetes are women, and this is a known risk factor for AD in other populations. Indigenous women also suffer from lower literacy rates and median income than non-Indigenous women [139]. And like their American counterparts, Indigenous women in Canada suffer more from the effects of historical inequities. Before the Indian Act of 1867, many Indigenous communities in Canada were matriarchal and matrilineal [140]. Women ran the household and descent was traced through the maternal line. Women were often powerful in their tribes and made decisions that had a direct impact on their communities. The Indian Act gave the Federal Government the power to define Indian Identity and they clearly discriminated against women, who became largely excluded from decision making and lost household and property rights [140]. Before amendments to the Act in 1985 (Bill C31) and future amendments in 2010 (Bill C-3: Gender Equity and the Indian Registration Act), a woman could be stripped of her "Indian" status by marrying a man who was not a status Indian, and a grandchild would be given Indian status if her Grandfather was Aboriginal, but not if her Mother was Aboriginal [140]. Other historical wrongs included the forcible separation of Indigenous children from their families and their placement into Residential Schools, which existed in Canada between 1830 and 1996 [88]. The children lost their respective languages and culture and sometimes experienced physical and sexual abuse, which greatly impacted both the children and especially female family members. This led to a mistrust of the Federal Government assigned to provide their medical care [88]. Forced sterilization of Canadian Aboriginal women has occurred as recently as 2018 and a class action lawsuit in Saskatchewan is currently ongoing in which at least 100 women have come forward to describe their stories [141-143]. And like American Indigenous women, Canadian Indigenous women are no strangers to violence. Indigenous women in Canada are 3.5 times more likely to experience violence than their non-Indigenous counterparts [140]. Women on reserves who experience violence feel a lack of support from police, the justice system and male tribe and council members, and often flee for the cities to escape [140]. Once there, they become vulnerable to risks that include sexual exploitation and further violence [140]. This cycle of violence against women, combined with historical inequities 
and gender-specific health issues leave many female elders with a sense of grief, depression, and hopelessness. Given all this, it should be no surprise that recruitment into AD RCTs are difficult and face many challenges.

\section{HOW TO IMPROVE ENROLLMENT IN AN AD RCT?}

Race- and sex-based disparities exist in current AD clinical trials, and many of the publications, government policies, documents, guidelines, and grey literature covered in this review have provided recommendations for increasing the enrollment and retention of racial minorities and women, with some publications specific to Indigenous populations. Some suggestions include:

\section{Improve AD diagnosis}

One cannot enroll a participant into an AD RCT unless they have been properly diagnosed with AD. Due to cultural, geographical, and socio-economic barriers, Indigenous people probably often have AD, but have not been diagnosed by a qualified health care professional. Some of the reasons for lack of proper diagnoses include:

Improper cognitive tools. Many cognitive screening tools (e.g., Montreal Cognitive Assessment, Mini-Mental State Examination) are not culturally sensitive (e.g., lack relevant words or pictures) and are not in a culturally appropriate language. They also fail to account for the effects socio-economic factors, levels of education, and the degree that particular health problems have on performance $[31,71-73,91,93$, 144].

Lack of culturally specific information. Brochures, pamphlets, or newsletters that explain the symptoms, diagnosis, and treatment options for $\mathrm{AD}$ are required to communicate with Indigenous populations and should be available in a language that is culturally sensitive and not insulting [31, 65, 91-93, 145].

Lack of proper training. Health care staff required to diagnose $\mathrm{AD}$ often don't live in the community full time, are not of the same race, or have not received culturally-sensitive training. Language is often a barrier in terms of communication with the elderly Indigenous population [72, 91-93].

Lack of access to clinics. Geographical isolation and lack of transportation to get to the clinic have been cited as an issue in the AD diagnosis of Indigenous and other minority populations $[85,91,92,94$,
95]. The development of Research Centers in the four remote Inuit regions of Canada are one way of providing access to a valuable function with regard to governing, licensing, and monitoring of research projects [146].

Lack of technology. The use of new technologies (called Digital Biomarkers), which includes smart phones, tablets, smart watches, rings and smart suits, could aid in the early diagnosis of $\mathrm{AD}$, especially in remote northern reserves. These technologies can monitor changes to movement, speech, language, autonomic nervous system, eye movement and behavior and pick up early symptoms of cognitive decline [147-149].

\section{Improve community relations}

Some literature we reviewed have specific recommendations to improve community relations between research personnel and Indigenous and other minority populations. More Indigenous live in Manitoba than any other province in Canada (14\%) [150, 151] and the University of Manitoba has an established relationship with the provincial Indigenous communities. In the University of Manitoba guidance document titled "Framework for Research Engagement with First Nation, Metis and Inuit Peoples", a framework for improved research enrollment includes recognition of the fours "Rs" (Respect, Relevance, Reciprocity, and Responsibility) along with recognition of the Indigenous ethics process and the providing of opportunities for education, training, mentorship, and practical research experience to community members [39]. Tri-Council Policy 2 (TCP2), Chapter 9 lays out the ethical guidelines for Community Engagement in Aboriginal Research [41]. The formation of tight community relations between the researcher and the potential participant can have a positive impact on enrollment in an $\mathrm{AD}$ RCT [31, 39, 65, 83, 84, 86, 88, 92, 98, 105, 146].

\section{Ownership of data}

Indigenous and other minorities often feel like "guinea pigs" that don't receive a direct benefit from clinical trials. In the University of Manitoba guidance document [140], First Nations have applied the OCAP principle of Research (Ownership, Control, Access and Possession). The TCP2 (Chapter 9, Article 9.17) lays out guidelines for Interpretation and Dissemination of Research Results in Aboriginal communities [41]. The "sharing" of data provides a 
stimulus to engage Indigenous populations in future RCT $[65,83,152]$.

\section{DISCUSSION}

This review confirms that race- and sex-based disparities exist as far as enrollment into AD RCTs, with these disparities more prevalent in the Indigenous populations of the US and Canada. Only one RCT in the US listed on the ClinicalTrials.gov site at the time of this review involve Indigenous tribes. No trials were registered in Canada. The Indigenous in both countries may be more prone to $\mathrm{AD}$ due to long standing inequities in access to healthcare and the physical, emotional, and psychological stresses associated with their history, their socio-economic disadvantages, and exposure to poor housing conditions, poverty, and geographical isolation. Indigenous women may also be more at risk for $\mathrm{AD}$ than men due to poorly addressed violence against them and the added stress of acting as caregivers. More needs to be done to improve the understanding of, prevention, diagnosis, and treatment of $\mathrm{AD}$ in these minority communities before improvements in $\mathrm{AD}$ RCT enrollment can occur, but many excellent guidelines exist that current Research Centers, Universities and Health Clinics can use to guide their RCT policy and improve future enrollment numbers.

\section{ACKNOWLEDGMENTS}

We thank Dr. Maria Teresa Ferretti, Chief Science Officer of the Women's Brain Project for a critical reading of the manuscript. The research was funded by Canadian Institutes of Health Research (CIHR), grant No. PJT-162144, and the St. Boniface Hospital Research Foundation, grant Nos. 1406-3216 and 1410-3216. This work was also supported by Research Manitoba (to BCA), and the Alzheimer's Society of Manitoba, thru the Honorable Douglas and Patricia Everett, and Royal Canadian Properties Limited Endowment Fund to Dr. Albensi. BCA holds the Manitoba Dementia Research Chair and is a Research Affiliate of the Centre on Aging at the University of Manitoba.

\section{CONFLICT OF INTEREST}

The authors have no conflict of interest to report.

\section{REFERENCES}

[1] Alzheimer's Association Website, https://www.alz.org/.

[2] Alzheimers.net 2019 Global and U.S Alzheimer's Statistics, https://www.alzheimers.net/.

[3] (2019) Alzheimer's Disease Facts and Figures: Alzheimer's Association Fact Sheet. Alzheimers Dement 15, 321.

[4] Burke CW, Biospace: Alzheimer's Report: Current Therapies, Peipline and Outlook, https://www.biospace. com/article/alzheimer-s-disease-insight-report-currenttherapies-drug-pipeline-and-outlook/, September 23, 2019.

[5] Manitoba, Canada and Global Dementia Stats, https:// alzheimer.mb.ca/about-dementia/disease-stats/, March 2018.

[6] Alzheimer Society Canada. Latest Stats and Figures, https://alzheimer.ca/en/Home/Get-involved/Advocacy/ Latest-info-stats, June 29, 2018.

[7] Alzforum Website: Debate over DSM-5 diagnostic criteria for AD definition, http://www/alzforum.org, 2019.

[8] Jack CR, Jr., Bennett DA, Blennow K, Carrillo MC, Dunn B, Haeberlein SB, Holtzman DM, Jagust W, Jessen F, Karlawish J, Liu E, Molinuevo JL, Montine T, Phelps C, Rankin KP, Rowe CC, Scheltens P, Siemers E, Snyder HM, Sperling R, Contributors (2018) NIA-AA Research Framework: Toward a biological definition of Alzheimer's disease. Alzheimers Dement 14, 535-562.

[9] McKhann GM, Knopman DS, Chertkow H, Hyman BT, Jack CR, Jr., Kawas CH, Klunk WE, Koroshetz WJ, Manly JJ, Mayeux R, Mohs RC, Morris JC, Rossor MN, Scheltens P, Carrillo MC, Thies B, Weintraub S, Phelps CH (2011) The diagnosis of dementia due to Alzheimer's disease: Recommendations from the National Institute on Aging-Alzheimer's Association workgroups on diagnostic guidelines for Alzheimer's disease. Alzheimers Dement 7, 263-269.

[10] Vaughn P, NIA-AA 2011 Guidelines for Diagnosis of AD: Alzheimer's Disease Diagnostic Guidelines, https://www.nia.nih.gov/news/alzheimers-diagnosticguidelines-updated-first-time-decades, April 19, 2011.

[11] Carr T, The hard truth about Alzheimer's drugs. Aricept, Exelon, and Razadyne do little to help most people and post risks, https://www.consumerreports.org/cro/news/ 2014/04/aricept-exelon-and-razadyne-do-little-to-helpmost-people-and-pose-risks/index.htm, April 16, 2014.

[12] Burke CW, Biospace: Insight Report: Potential Therapeutic Targets for Alzheimer's., http://www.biospace. com/article-insight-report-poter, October 29, 2019.

[13] Nelson PT, Alafuzoff I, Bigio EH, Bouras C, Braak H, Cairns NJ, Castellani RJ, Crain BJ, Davies P, Del Tredici K, Duyckaerts C, Frosch MP, Haroutunian V, Hof PR, Hulette CM, Hyman BT, Iwatsubo T, Jellinger KA, Jicha GA, Kövari E, Kukull WA, Leverenz JB, Love S, Mackenzie IR, Mann DM, Masliah E, McKee AC, Montine TJ, Morris JC, Schneider JA, Sonnen JA, Thal DR, Trojanowski JQ, Troncoso JC, Wisniewski T, Woltjer RL, Beach TG (2012) Correlation of Alzheimer disease neuropathologic changes with cognitive status: A review of the literature. J Neuropathol Exp Neurol 71, 362-381.

[14] Nelson PT, Braak H, Markesbery WR (2009) Neuropathology and cognitive impairment in Alzheimer disease: A complex but coherent relationship. $\mathrm{J} \mathrm{Neu}$ ropathol Exp Neurol 68, 1-14. 
[15] Nelson PT, Dickson DW, Trojanowski JQ, Jack CR, Boyle PA, Arfanakis K, Rademakers R, Alafuzoff I, Attems J, Brayne C, Coyle-Gilchrist ITS, Chui HC, Fardo DW, Flanagan ME, Halliday G, Hokkanen SRK, Hunter S, Jicha GA, Katsumata Y, Kawas CH, Keene CD, Kovacs GG, Kukull WA, Levey AI, Makkinejad N, Montine TJ, Murayama S, Murray ME, Nag S, Rissman RA, Seeley WW, Sperling RA, White Iii CL, Yu L, Schneider JA (2019) Limbic-predominant age-related TDP-43 encephalopathy (LATE): Consensus working group report. Brain 142, 1503-1527.

[16] Zhang L, Chen Y, Liu M, Wang Y, Peng G (2019) TDP-43 and limbic-predominant age-related TDP-43 encephalopathy. Front Aging Neurosci 11, 376.

[17] Cummings J, Feldman HH, Scheltens P (2019) The "rights" of precision drug development for Alzheimer's disease. Alzheimers Res Ther 11, 76.

[18] Huang LK, Chao SP, Hu CJ (2020) Clinical trials of new drugs for Alzheimer disease. J Biomed Sci 27, 18.

[19] Mehta D, Jackson R, Paul G, Shi J, Sabbagh M (2017) Why do trials for Alzheimer's disease drugs keep failing? A discontinued drug perspective for 2010-2015. Expert Opin Investig Drugs 26, 735-739.

[20] Thompson D, Medical XPress Webiste: More Alzheimer's drug trial failures: Are researchers on the wrong track? https://medicalxpress.com/news/201904-alzheimer-drugtrial-failures-wrong.html, April 10, 2019.

[21] Cortes LR, Cisternas CD, Forger NG (2019) Does gender leave an epigenetic imprint on the brain? Front Neurosci 13, 173.

[22] Hartman RJG, Huisman SE, den Ruijter HM (2018) Sex differences in cardiovascular epigenetics-a systematic review. Biol Sex Differ 9, 19.

[23] Kaiser J, The Alzheimer's Gamble: NIH tries to turn billions in new funding into treatment for deadly brain disease, https://www.sciencemag.org/news/2018/08/ alzheimer-s-gamble-nih-tries-turn-billions-new-fundingtreatment-deadly-brain-disease, August 30, 2018.

[24] Shugart J, Senate Ups Funding for Alzheimer's Research by $\$ 350$ million for 2020, https://www.alzforum.org/ news/community-news/senate-ups-funding-

alzheimers-research-350-million-2020, December 23, 2019.

[25] Alzheimer Society of Canada awards $\$ 2.1$ million to Canadian dementia researchers and launches new competition, https://www.newswire.ca/news-releases/alzheimersociety-of-canada-awards-2-1-million-to-canadiandementia-researchers-and-launches-new-competition848319820.html, September 26, 2019.

[26] Brain Canada Foundation Grant Information Page, https://braincanada.ca/about-us/our-programs/, 2020.

[27] CIHR Dementia Research Strategy Funding, https://cihrirsc.gc.ca/e/46234.html, May 20, 2020.

[28] Public Health Agency of Canada, A Dementia Strategy for Canada: Together We Aspire, https://www.canada. ca/en/public-health/services/publications/diseasesconditions/dementia-strategy.html, June 2019.

[29] Doraiswamy JSPM, Underrepresentation of AfricanAmericans in Alzheimer's Trials: A Call for Affirmative Action, https://www.frontiersin.org/articles/10.3389/ fnagi.2016.00123/full, June 3, 2016.

[30] Eibelman J, Language Barrier Means Millions of Elderly Can't Access Alzheimer's Trials, https://www.npr.org/ sections/health-shots/2018/10/31/660286786/languagebarrier-means-millions-of-elderly-cant-access-

alzheimers-trials, October 31, 2018.

[31] Gilmore-Bykovskyi AL, Jin Y, Gleason C, FlowersBenton S, Block LM, Dilworth-Anderson P, Barnes LL, Shah MN, Zuelsdorff M (2019) Recruitment and retention of underrepresented populations in Alzheimer's disease research: A systematic review. Alzheimers Dement (N Y) 5, 751-770.

[32] Graham LA, Ngwa J, Ntekim O, Ogunlana O, Wolday S, Johnson S, Johnson M, Castor C, Fungwe TV, Obisesan TO (2018) Best strategies to recruit and enroll elderly Blacks into clinical and biomedical research. Clin Interv Aging 13, 43-50.

[33] Resendez J, Monroe S, A road map for including Latinos and African Americans in Alzheimer's research, https://www.statnews.com/2019/10/11/alzheimersresearch-roadmap-inclusion/, Accessed October 11, 2019.

[34] Pariera KL, Murphy ST, Meng J, McLaughlin ML (2017) Exploring willingness to participate in clinical trials by ethnicity. J Racial Ethn Health Disparities 4, 763-769.

[35] Novak K, Riggs J, Alzheimer's Assocation, Hispanics/Latinos and Alzheimer's Disease: Report.

[36] Strobel G, Alzheimer's Researchers Seek Advice on How to Include African-Americans, https://www.alzforum. org/news/conference-coverage/alzheimers-researchersseek-advice-how-include-african-americans, October 26, 2018.

[37] Williams MM, Meisel MM, Williams J, Morris JC (2011) An interdisciplinary outreach model of African American recruitment for Alzheimer's disease research. Gerontologist 51 Suppl 1, S134-141.

[38] World Health Organization Health Topics: Indigenous Populations, https://www.who.int/topics/health_services_ indigenous/en/, Accessed April 17, 2014.

[39] Cook CL, First Nations, Metis and Inuit Health, http:// umanitoba.ca/faculties/health_sciences/medicine/fnmi_ health/.

[40] Government of Canada Constitution Act (1982): Section 35; Part II: Rights of the Aboriginal Peoples of Canada, https://laws.justice.gc.ca/eng/, May 14, 2020.

[41] Governement of Canada TCP2 (2018): Chapter 9: Research Involving the First Nations, Inuit and Metis Peoples of Canada, https://ethics.gc.ca/eng/tcps2eptc2_2018_chapter9-chapitre9.html.

[42] Canadian Dementia Research Priorities - Report of the Canadian Dementia Priority Setting Partnership,The Alzheimer Society Canada; The Canadian Consortium on Neurodegeneration in Aging; The Toronto Rehabilitation Institute, http://alzheimer.ca/sites/default/files/2018-01/ Dementia\%2OPSP\%20Report\%20ENG\%20Dec\%20 Final\%20SCREEN_0.pdf.

[43] ClinicalTrials.gov NIH U.S National Library of Medicine, https://www.clinicaltrials.gov/.

[44] Dementia in Canada: Summary, https://www.cihi.ca/en/ dementia-in-canada/dementia-in-canada-summary.

[45] Tyas SL, Manfreda J, Strain LA, Montgomery PR (2001) Risk factors for Alzheimer's disease: A population-based, longitudinal study in Manitoba, Canada. Int J Epidemiol 30, 590-597.

[46] Chapter 2: The State of Clinical Research in the United States: An Overview from Transforming Clinical Research in the United States: Challenges and Opportunities: Workshop Summary. 
[47] Cummings J, Aisen P, Barton R, Bork J, Doody R, Dwyer J, Egan JC, Feldman H, Lappin D, Truyen L, Salloway S, Sperling R, Vradenburg G (2016) Re-engineering Alzheimer clinical trials: Global Alzheimer's Platform Network. J Prev Alzheimers Dis 3, 114-120.

[48] Chapter 3: Challenges in Clinical Research from Transforming Clinical Research in the United States: Challenges and Opportunities: Workshop Summary, Institute of Medicine (U.S) Forum on Drug Discovery, Development and Translation.

[49] Lindley RI (2012) Drug trials for older people. J Gerontol A Biol Sci Med Sci 67, 152-157.

[50] Mody L, Miller DK, McGloin JM, Freeman M, Marcantonio ER, Magaziner J, Studenski S (2008) Recruitment and retention of older adults in aging research. $J$ Am Geriatr Soc 56, 2340-2348.

[51] Ridda I, MacIntyre CR, Lindley RI, Tan TC (2010) Difficulties in recruiting older people in clinical trials: An examination of barriers and solutions. Vaccine 28, 901906.

[52] Heneghan C, Goldacre B, Mahtani KR (2017) Why clinical trial outcomes fail to translate into benefits for patients. Trials 18, 122.

[53] Eichler HG, Sweeney F (2018) The evolution of clinical trials: Can we address the challenges of the future? Clin Trials 15, 27-32.

[54] Shenoy P, Harugeri A (2015) Elderly patients' participation in clinical trials. Perspect Clin Res 6, 184-189.

[55] Older People Projected to Outnumber Children for First Time in U.S. History, https://www.census.gov/ newsroom/press-releases/2018/cb18-41-populationprojections.html, March 13, 2018.

[56] Banzi R, Camaioni P, Tettamanti M, Bertele V, Lucca U (2016) Older patients are still under-represented in clinical trials of Alzheimer's disease. Alzheimers Res Ther 8, 32 .

[57] Wright K, Research Review: Upper Age Limit in Clinical Trials - Research Data Lacking With Older Adults for Evidence-Based Medicine, https://www. todaysgeriatricmedicine.com/archive/MA19p30.shtml.

[58] Espeland MA, Crimmins EM, Grossardt BR, Crandall JP, Gelfond JA, Harris TB, Kritchevsky SB, Manson JE, Robinson JG, Rocca WA, Temprosa M, Thomas F, Wallace R, Barzilai N, Multimorbidity Clinical Trials C (2017) Clinical trials targeting aging and age-related multimorbidity. J Gerontol A Biol Sci Med Sci 72, 355-361.

[59] McHenry JC, Insel KC, Einstein GO, Vidrine AN, Koerner KM, Morrow DG (2015) Recruitment of older adults: Success may be in the details. Gerontologist 55, 845-853.

[60] Ridda I, Lindley R, MacIntyre RC (2008) The challenges of clinical trials in the exclusion zone: The case of the frail elderly. Australas J Ageing 27, 61-66.

[61] Grill JD, Karlawish J (2010) Addressing the challenges to successful recruitment and retention in Alzheimer's disease clinical trials. Alzheimers Res Ther 2, 34.

[62] Participation in Dementia Trials and Studies: Challenges and Recommendations,Alzheimer's Disease International, https://www.alz.co.uk/dementia-plans/globalplan\#: :text=The $\% 20$ plan $\% 20$ follows $\% 2010 \% 20$ years, dementia\%20on\%20communities\%20and\%20countries

[63] Carr SA, Davis R, Spencer D, Smart M, Hudson J, Freeman S, Cooper GE, Schmitt FA, Markesbery WR, Danner D, Jicha GA (2010) Comparison of recruitment efforts targeted at primary care physicians versus the community at large for participation in Alzheimer disease clinical trials. Alzheimer Dis Assoc Disord 24, 165-170.
[64] Wilson RS, Krueger KR, Arnold SE, Schneider JA, Kelly JF, Barnes LL, Tang Y, Bennett DA (2007) Loneliness and risk of Alzheimer's disease. Arch Gen Psychiatry 64, 234-240.

[65] Haring RC, Henry WA, Hudson M, Rodriguez EM, Taualii M (2018) Views on clinical trial recruitment, biospecimen collection, and cancer research: Population science from landscapes of the Haudenosaunee (People of the Longhouse). J Cancer Educ 33, 44-51.

[66] Saini M, Quinn A (2013) A systematic review of randomized controlled trials of health related issues within an Aboriginal context. National Collaborating Centre for Aboriginal Health.

[67] Matthews KA, Xu W, Gaglioti AH, Holt JB, Croft JB, Mack D, McGuire LC (2019) Racial and ethnic estimates of Alzheimer's disease and related dementias in the United States (2015-2060) in adults aged $>/=65$ years. Alzheimers Dement 15, 17-24.

[68] Profile: American Indian/Alaska Native, https:// minorityhealth.hhs.gov/omh/browse.aspx?lvl=3\&lvlid $=62$, March 28, 2018.

[69] American Indian and Alaska Native Heritage Month: November 2018, American Profile Facts for Features, https://www.census.gov/content/dam/Census/newsroom/ stories/2018/aian.pdf, October 25, 2018.

[70] Native Americans by the Numbers, https://www. infoplease.com/history/native-american-heritage/nativeamericans-by-the-numbers, February 28, 2017, Accessed February 28, 2017.

[71] Griffin-Pierce T, Silverberg N, Connor D, Jim M, Peters J, Kaszniak A, Sabbagh MN (2008) Challenges to the recognition and assessment of Alzheimer's disease in American Indians of the southwestern United States. Alzheimers Dement 4, 291-299.

[72] Healthy Brain Initiative (2019) Alzheimer's Association and Centers for Disease Control and Prevention.

[73] Emerging LTSS Issues in Indian Country: Alzheimer's and Dementia, https://www.dhs.wisconsin.gov/adrc/ dementia-care-specialist-program.htm, May 13, 2016.

[74] Mayeda ER, Glymour MM, Quesenberry CP, Whitmer RA (2016) Inequalities in dementia incidence between six racial and ethnic groups over 14 years. Alzheimers Dement 12, 216-224.

[75] Shannon S, Native Americans Not Genetically Predisposed to Develop Alzheimer's Disease, KGOU BBC Newshour, https://www.kgou.org/post/native-americansnot-genetically-pre-disposed-develop-alzheimer-sdisease, December 5, 2014.

[76] Manly JJ, Mayeux R (2004) Chapter 4: Ethnic differences in dementia and Alzheimer's disease. In Critical Perspectives on Racial and Ethnic Differences in Health in Late Life. The National Academies Press, Washington, DC.

[77] Alzheimer's Disease and Healthy Aging Data Portal, https://www.cdc.gov/aging/agingdata/index.html.

[78] Weiner MF, Hynan LS, Rossetti H, Womack KB, Rosenberg RN, Gong YH, Qu BX (2011) The relationship of cardiovascular risk factors to Alzheimer disease in Choctaw Indians. Am J Geriatr Psychiatry 19, 423-429.

[79] Lehnardt K, 94 Interesting Native American Facts, https://www.factretriever.com/native-american-facts, September 9, 2019, Accessed September 15, 2016.

[80] New Detailed Statistics on Race, Hispanic Origin, Ancestry and Tribal Groups, United States Census 
Bureau, https://www.census.gov/newsroom/pressreleases/2017/acs-selected-population-tables-aian.html, July 13, 2017.

[81] Garrett MD, Baldridge D, Benson W, Crowder J, Aldrich N (2015) Mental health disorders among an invisible minority: Depression and dementia among american Indian and alaska native elders. Gerontologist 55, 227-236.

[82] Ernst AJ (2008) Native American Center for Excellence, Environmental Scan Report.

[83] Petereit DG, Burhansstipanov L (2008) Establishing trusting partnerships for successful recruitment of American Indians to clinical trials. Cancer Control 15, 260-268.

[84] Barriers to Native Participation in Clinical Trials, http://natamcancer.org/page155.html, February 24, 2016.

[85] Sprague D, Russo J, LaVallie DL, Buchwald D (2013) Barriers to cancer clinical trial participation among American Indian and Alaska Native tribal college students. J Rural Health 29, 55-60.

[86] Buchwald D, Mendoza-Jenkins V, Croy C, McGough H, Bezdek M, Spicer P (2006) Attitudes of urban American Indians and Alaska Natives regarding participation in research. J Gen Intern Med 21, 648-651.

[87] Aboriginal Peoples in Canada: Key Results from the 2016 Census, https://www150.statcan.gc.ca/n1/dailyquotidien/171025/dq171025a-eng.pdf, Accessed October 25, 2017.

[88] Sinclair D, Schulz M. Aboriginal Communities and Alzheimer Societies in Canada: Building an awareness of existing challenges to effective service provision. Alzheimer Society Canada.

[89] Mccue HA, Parrott Z, The Canadian Encyclopedia Online Publication: Reserves., https://www.thecanadian encyclopedia.ca/en/article/aboriginal-reserves, July 12, 2018, Accessed May 31, 2011.

[90] Stats Canada: Total population by Aboriginal Identity and Registered or Treaty Indian Status, Canada, 2016, https://www12.statcan.gc.ca/census-recensement/ 2016/as-sa/fogs-spg/Facts-CAN-eng.cf

[91] Petrasek MacDonald J, Ward V, Halseth R (2018) Alzheimer's disease and related dementias in indigenous populations in Canada: Prevalence and risk factors. National Collaborating Centre for Aboriginal Health.

[92] Jacklin K, Walker J (2020) Cultural understandings of dementia in Indigenous peoples: A qualitative evidence synthesis. Can J Aging 39, 220-234.

[93] Jacklin K, Warry W, Blind M (2014) Perceptions of Alzheimer's Disease and Related Dementias Among Aboriginal Peoples in Ontario. Sudbury Community Report, Northern Ontario School of Medicine.

[94] Halseth R (2018) Overcoming barriers to culturally safe and appropriate dementia care services and supports for Indigenous peoples in Canada. National Collaborating Centre for Aboriginal Health.

[95] Walker JD, Andrew M, Bronskill S, Smylie J, Warry W, Henry D. Loft D, Jones C, Sutherland R, Blind M, Slater M, Pitawanakwat K, Mecredy G, Jacklin K (2019) Ontario First Nations Aging Study: Overview and Report. Sudbury: Ontario First Nations Aging Study.

[96] MacDonald JP, Barnes DE, Middleton LE (2015) Implications of risk factors for Alzheimer's disease in Canada's Indigenous population. Can Geriatr J 18, 152-158.

[97] Alcock DE (2019) 'I Honoured Him Until the End': Storytelling of Indigenous Female Caregivers and Care Providers Focused on Alzheimer's Disease and Other Dementias (ADOD). Graduate Program in Anthropology,
The University of Western Ontario; Western Graduate and Postdoctural Studies, Electronic Thesis and Dissertation Repository 6521.

[98] Illes J (2013) Ethical dilemma in dementia care: Does culture matter? Conference CDC Vancouver 2013.

[99] Rocca WA, Mielke MM, Vemuri P, Miller VM (2014) Sex and gender differences in the causes of dementia: A narrative review. Maturitas 79, 196-201.

[100] Andrew MK, Tierney MC (2018) The puzzle of sex, gender and Alzheimer's disease: Why are women more often affected than men? Womens Health 14, 174550651881799.

[101] Chambers LW, Bancej C, McDowell I (2016) Prevalence and Monetary Costs of Dementia in Canada. Population Health Expert Panel, Alzheimer Society Canada and Public Health Agency of Canada.

[102] Nebel RA, Aggarwal NT, Barnes LL, Gallagher A, Goldstein JM, Kantarci K, Mallampalli MP, Mormino EC, Scott L, Yu WH, Maki PM, Mielke MM (2018) Understanding the impact of sex and gender in Alzheimer's disease: A call to action. Alzheimers Dement 14, 1171-1183.

[103] Liu KA, Mager NA (2016) Women's involvement in clinical trials: Historical perspective and future implications. Pharm Pract (Granada) 14, 708.

[104] Medeiros AM, Silva RH (2019) Sex differences in Alzheimer's disease: Where do we stand? J Alzheimers Dis 67, 35-60.

[105] Burke JF, Brown DL, Lisabeth LD, Sanchez BN, Morgenstern LB (2011) Enrollment of women and minorities in NINDS trials. Neurology 76, 354-360.

[106] Yakerson A (2019) Women in clinical trials: A review of policy development and health equity in the Canadian context. Int J Equity Health 18, 56.

[107] Devlin H, Use of male mice skews drug research against women, study finds. Male animal bias is unjustified and can lead to drugs that work less well for women, The Guardian International Edition, https://www.theguardian. com/science/2019/may/31/sexist-research-means-drugsmore-tailored-to-men-says-scientist, Accessed May 31, 2019.

[108] LaFerla FM, Green KN (2012) Animal models of Alzheimer disease. Cold Spring Harb Perspect Med 2, a006320.

[109] Agrawal S, Alzheimer's Disease: Animal Research Models, Labcome, https://www.labome.com/method/ Alzheimer-s-Disease-Animal-Research-Models.html, January 16, 2020, Accessed April 7, 2017.

[110] Schaeffer EL, Figueiro M, Gattaz WF (2011) Insights into Alzheimer disease pathogenesis from studies in transgenic animal models. Clinics (Sao Paulo) 66 (Suppl 1), 45-54.

[111] Sasaguri H, Nilsson P, Hashimoto S, Nagata K, Saito T, De Strooper B, Hardy J, Vassar R, Winblad B, Saido TC (2017) APP mouse models for Alzheimer's disease preclinical studies. EMBO J 36, 2473-2487.

[112] Rozenbaum M, Why we need female mice in drug trials, Understanding Animal Research, https://www.under standinganimalresearch.org.uk/news/communicationsmedia/why-we-need-female-mice-in-drug-trials/, Accessed March 8, 2019.

[113] Buch T, Moos K, Ferreira FM, Fröhlich H, Gebhard C, Tresch A (2019) Benefits of a factorial design focusing on inclusion of female and male animals in one experiment. J Mol Med 97, 871-877.

[114] Krisch JA, How Much Do Sex Differences Matter in Mouse Studies? Examining both male and female model 
organisms is worth the extra effort and added costs, most experts maintain but whether the results translate to human studies is less clear, The Scientist, https://www. the-scientist.com/news-analysis/how-much-do-sexdifferences-matter-in-mouse-studies-31974, Accessed February 23, 2017.

[115] Pigg S, Research controversy: Male mice used to study diseases that affect women, The Star, https://www. thestar.com/life/health_wellness/2011/03/29/research_ controversy_male_mice_used_to_study_diseases_that_ affect_women.html, Accessed March 19, 2011.

[116] Sokic N, Double the number of women suffer from dementia - so why are even the lab rats in brain studies male? National Post (Toronto), https://nationalpost.com/health/ double-the-number-of-women-suffer-from-dementiaso-why-are-even-the-lab-rats-in-brain-studies-male, Accessed December 4, 2019.

[117] Bories C, Guitton MJ, Julien C, Tremblay C, Vandal M, Msaid M, De Koninck Y, Calon F (2012) Sex-dependent alterations in social behaviour and cortical synaptic activity coincide at different ages in a model of Alzheimer's disease. PLoS One 7, e46111.

[118] Djordjevic J, Thomson E, Chowdhury SR, Snow WM, Perez C, Wong TP, Fernyhough P, Albensi BC (2017) Brain region- and sex-specific alterations in mitochondrial function and NF-kappaB signaling in the TgCRND8 mouse model of Alzheimer's disease. Neuroscience 361, 81-92.

[119] Dodiya HB, Kuntz T, Shaik SM, Baufeld C, Leibowitz J, Zhang X, Gottel N, Zhang X, Butovsky O, Gilbert JA, Sisodia SS (2019) Sex-specific effects of microbiome perturbations on cerebral Abeta amyloidosis and microglia phenotypes. J Exp Med 216, 1542-1560.

[120] Jankowsky JL, Zheng H (2017) Practical considerations for choosing a mouse model of Alzheimer's disease. $\mathrm{Mol}$ Neurodegener 12, 89.

[121] Yang JT, Wang ZJ, Cai HY, Yuan L, Hu MM, Wu MN, Qi JS (2018) Sex differences in neuropathology and cognitive behavior in APP/PS1/tau triple-transgenic mouse model of Alzheimer's disease. Neurosci Bull 34, 736-746.

[122] Yao J, Irwin RW, Zhao L, Nilsen J, Hamilton RT, Brinton RD (2009) Mitochondrial bioenergetic deficit precedes Alzheimer's pathology in female mouse model of Alzheimer's disease. Proc Natl Acad Sci US A 106, 1467014675.

[123] Ferretti MT, Iulita MF, Cavedo E, Chiesa PA, Schumacher Dimech A, Santuccione Chadha A, Baracchi F, Girouard H, Misoch S, Giacobini E, Depypere H, Hampel $\mathrm{H}$, Women's Brain Project and the Alzheimer Precision Medicine Initiative (2018) Sex differences in Alzheimer disease - the gateway to precision medicine. Nat Rev Neurol 14, 457-469.

[124] Li R, Singh M (2014) Sex differences in cognitive impairment and Alzheimer's disease. Front Neuroendocrinol 35, 385-403.

[125] World Alzheimer's Day: The Importance of Studying Sex Differences, Women's Health Research Institute at BC Women's, http://whri.org/world-alzheimers-daythe-importance-of-studying-sex-differences/, Accessed September 21, 2019.

[126] Oveisgharan S, Arvanitakis Z, Yu L, Farfel J, Schneider JA, Bennett DA (2018) Sex differences in Alzheimer's disease and common neuropathologies of aging. Acta Neuropathol 136, 887-900.
[127] Buckley RF, Mormino EC, Rabin JS, Hohman TJ, Landau S, Hanseeuw BJ, Jacobs HIL, Papp KV, Amariglio RE, Properzi MJ, Schultz AP, Kirn D, Scott MR, Hedden T, Farrell M, Price J, Chhatwal J, Rentz DM, Villemagne VL, Johnson KA, Sperling RA (2019) Sex differences in the association of global amyloid and regional tau deposition measured by positron emission tomography in clinically normal older adults. JAMA Neurol 76, 542-551.

[128] Bennett DA, Schneider JA, Arvanitakis Z, Wilson RS (2012) Overview and findings from the Religious Orders Study. Curr Alzheimer Res 9, 628-645.

[129] Bennett DA, Schneider JA, Buchman AS, Barnes LL, Boyle PA, Wilson RS (2012) Overview and findings from the Rush Memory and Aging Project. Curr Alzheimer Res 9, 646-663.

[130] Fogel DB (2018) Factors associated with clinical trials that fail and opportunities for improving the likelihood of success: A review. Contemp Clin Trials Commun 11, 156-164.

[131] Ellison JM, Alzheimer's Disease and Women: A Research Update,Bright Focus Foundation, https:// www.brightfocus.org/alzheimers/article/alzheimersdisease-and-women-research-update, November 25 , 2019, Accessed November 14, 2016.

[132] Clinical Trials: Benefits, Risks and Safety, National Institute on Aging (U.S Department of Health and Human Services), https://www.nia.nih.gov/.

[133] Rahman A, Schelbaum E, Hoffman K, Diaz I, Hristov H, Andrews R, Jett S, Jackson H, Lee A, Sarva H, Pahlajani S, Matthews D, Dyke J, de Leon MJ, Isaacson RS, Brinton RD, Mosconi L (2020) Sex-driven modifiers of Alzheimer risk: A multimodality brain imaging study. Neurology $\mathbf{9 5}$, e166-e178.

[134] (2010) AARP/NAC 2009 survey on caregiving in the United States. In Alzheimer's in America. The Shriver Report on Women and Alzheimer's. Free Press, New York, pp. 107-126.

[135] Carcel C, Woodward M, Balicki G, Koroneos GL, Sousa DA, Cordonnier C, Lukaszyk C, Thompson K, Wang X, Davies L, Bassi M, Anderson CS, Peters SA, Sandset EC (2019) Trends in recruitment of women and reporting of sex differences in large-scale published randomized controlled trials in stroke. Int J Stroke 14, 931-938.

[136] Carter CL, Resnick EM, Mallampalli M, Kalbarczyk A (2012) Sex and gender differences in Alzheimer's disease: Recommendations for future research. $J$ Womens Health (Larchmt) 21, 1018-1023.

[137] Salam M, Native American Women are Facing a Crisis, New York Times, https://www.nytimes.com/2019/04/12/ us/native-american-women-violence.html, Accessed April 12, 2019.

[138] Ending Violence Against Native Women, Indian Law Resource Center, https://indianlaw.org/issue/endingviolence-against-native-women.

[139] Arriagada P, First Nations, Metis and Inuit Women, https://www150.statcan.gc.ca/n1/pub/89-503x/2015001/article/14313-eng.htm, Accessed February 23, 2016.

[140] Halseth R (2013) Aboriginal Women in Canada: Gender, socio-economic determinants of health, and initiatives to close the wellness-gap. National Collaborating Centre for Aboriginal Health.

[141] Forced Sterilization of Indigenous Women in Canada, International Justice Resource Centre, https://ijrcenter. 
org/forced-sterilization-of-indigenous-women-incanada/.

[142] Zingel A (2019) Indigenous women come forward with accounts of forced sterilization, says lawyer. $C B C$ News, https://www.cbc.ca/news/canada/north/forcedsterilization-lawsuit-could-expand-1.5102981

[143] Ward D (2020) Forced sterilization a symptom of 'colonial hangover' says lawyer. APTN National News, https://www.aptnnews.ca/facetoface/forced-sterilizationa-symptom-of-colonial-hangover-says-lawyer/

[144] Whyte SR, Cullum CM, Hynan LS, Lacritz LH, Rosenberg RN, Weiner MF (2005) Performance of elderly Native Americans and Caucasians on the CERAD Neuropsychological Battery. Alzheimer Dis Assoc Disord 19, 74-78.

[145] Webkamigad S, Warry W, Blind M, Jacklin K (2020) An approach to improve dementia health literacy in Indigenous communities. J Cross Cult Gerontol 35, 69-83.

[146] (2018) National Inuit Strategy on Research. Inuit Tapiriit Kanatami (ITK).

[147] Kourtis LC, Regele OB, Wright JM, Jones GB (2019) Digital biomarkers for Alzheimer's disease: The mobile/ wearable devices opportunity. NPJ Digit Med 2, 9.
[148] Piau A, Wild K, Mattek N, Kaye J (2019) Current state of digital biomarker technologies for real-life, home-based monitoring of cognitive function for mild cognitive impairment to mild Alzheimer disease and implications for clinical care: Systematic review. J Med Internet Res 21, e12785.

[149] Turner RS, Stubbs T, Davies DA, Albensi BC (2020) Potential new approaches for diagnosis of Alzheimer's disease and related dementias. Front Neurol 11, 496.

[150] Adlimoghaddam A, Roy B, Albensi BC (2018) Future trends and the economic burden of dementia in Manitoba: Comparison with the rest of Canada and the World. Neuroepidemiology 51, 71-81.

[151] Chernikova E, Aboriginal peoples: Fact Sheets for Manitoba, https://www150.statcan.gc.ca/n1/pub/89-656x/89-656-x2016008-eng.htm, March 14, 2016.

[152] Maar MA, Beaudin V, Yeates K, Boesch L, Liu P, Madjedi K, Perkins N, Hua-Stewart D, Beaudin F, Wabano MJ, Tobe SW (2019) Wise practices for cultural safety in electronic health research and clinical trials with Indigenous people: Secondary analysis of a randomized clinical trial. J Med Internet Res 21, e14203. 